\title{
McVay, Mikkelsen, and Nemanich to Chair 1989 MRS Fall Meeting Roster of Technical Symposia in Process
}

Gary L. McVay, James C. Mikkelsen, Jr., and Robert J. Nemanich have taken on the task of chairing the upcoming 1989 MRS Fall Meeting. The meeting, with a full complement of technical symposia and short courses, is scheduled November 27 - December 2, 1989 at the Boston Marriott and Westin Hotels/Copley Place, Boston, Massachusetts.

Gary L. McVay is currently manager of the Materials Sciences Department at Pacific Northwest Laboratory (PNL), Richland, Washington. He received his $\mathrm{PhD}$ in ceramics from the University of Missouri in 1970. McVay was a research staff member at both Sandia National Laboratories/ Albuquerque and Argonne National Laboratory before joining PNL in 1978. His research interests include amorphous materials, materials synthesis, and biologically produced materials. He is the author of over 50 open literature publications and the editor of three symposia proceedings. $\mathrm{He}$ has been active in the Materials Research Society since 1982 and has served on several committees in addition to being an organizer for the MRS symposium on the "Scientific Basis for Nuclear Waste Management VII."

James C. Mikkelsen, Jr. is an area manager and principal scientist of the Electronics and Imaging Laboratory at Xerox's Palo Alto Research Center in California. His responsibilities include process development and fabrication of large area thin-film electronic devices. Mikkelsen received his $\mathrm{PhD}$ in chemistry from Brown University in 1970. Before coming to Xerox in 1974 he worked on CCD imaging at Bell Laboratories, Murray Hill, New Jersey and on nonlinear optical materials at Lincoln Laboratory. He has collaborated on and led a wide variety of materials science research projects on semiconducting, insulating, magnetic, optical, and superionicconducting materials. Mikkelsen's previous MRS activities include co-chairing the 1985 MRS Fall Symposium on "Oxygen, Carbon, Hydrogen, and Nitrogen in Crystalline Silicon."

Robert J. Nemanich is an associate professor in the Department of Physics and the Department of Materials Science and Engineering at North Carolina State University, Raleigh, North Carolina. His current research interests include the initial stages of heteroepitaxy and particularly expitaxial silicide/Si, characterization of diamond film growth processes, and microcrystalline and amorphous semicon-

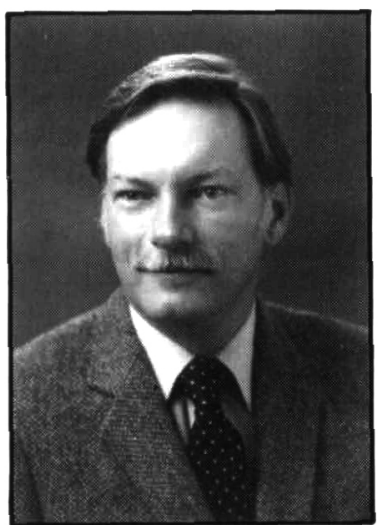

Gary L. McVay

Materials Sciences

Department

Battelle-Pacific Northwest

Laboratories

P.O. Box 999

Richland, WA 99352

(509) 375-3762

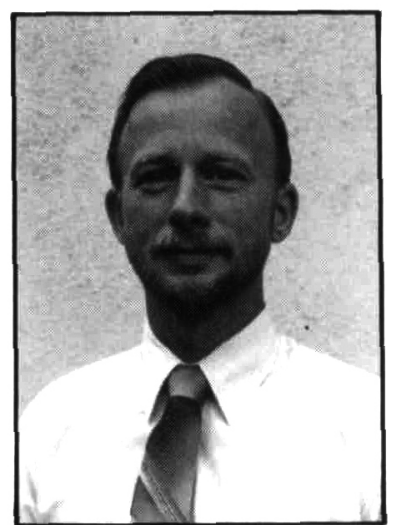

James Mikkelsen, Jr.

Xerox-Palo Alto Research

Center

Electronics and Imaging

Laboratory

Palo Alto, CA 94304

(415) 494-4917

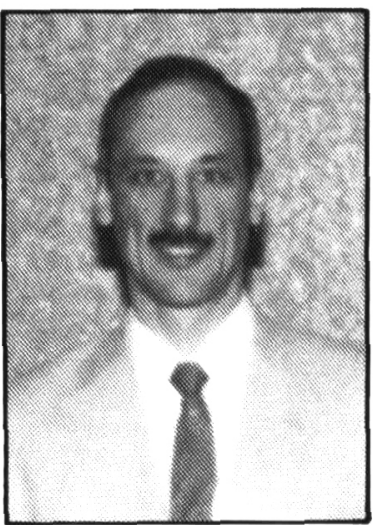

Robert J. Nemanich Department of Physics North Carolina State

University

Box 8202

Raleigh, NC 27695-8202

(919) $737-3225$ ducting films. Before coming to the university, Nemanich was a senior member of the research staff and project leader in the Integrated Circuit Laboratory and General Sciences Laboratory at the Xerox Palo Alto Research Center. His work there centered on applying Raman scattering for characterization of semiconducting thin films and growth processes. Nemanich is on the MRS Publications Committee and has been a co-chair of two MRS symposia, "Thin Films - Interfaces and Phenomena," and "Heteroepitaxy on Si: Fundamentals, Structures and Devices."

Technical symposia under consideration for the 1989 Fall Meeting include the following:

A-Beam-Solid Interactions: Physical Phenomena

B--Microscale In Situ Patterning and Selective Area Deposition

C-Atomic-Scale Structure of Interfaces

D-Superlattices and Layered Structures

E-Properties of II-VI Semiconductors: Bulk Crystals, Epitaxial Films, Quantum Well Structures, and Dilute Magnetic Systems

F-Diamond, Nitride, and Carbide Semiconducting Films

G-Deep Levels and Diffusion in Electronic Materials
$\mathrm{H}-$ Materials Issues in Microcrystalline Semiconducting Films

I-Characterization of Plasma Enhanced CVD Processes

J-Neutron Scattering Characterization of Materials

$\mathrm{K}$-Advanced Electronic Packaging Materials

L-Chemical Vapor Deposition of Refractory Materials

M-High Temperature Superconductors: Materials Processing, Properties and Characterization

$\mathrm{N}$-Tailored Interfaces in Composite Materials

O-Polymer-Based Molecular Composites

P-Optical Fiber Materials and Processes

Q-Transport and Magnetic Properties of Organic Conducting Crystals

R-Materials Synthesis Utilizing Biological Processes

S-Multi-Function Materials

T-Fractal Aspects of Materials

U-Materials Issues of Hazardous Waste Disposal

V-Complex Fluid Systems

Look for 1989 Fall Meeting details in upcoming issues of the MRS BULLETIN. 